\title{
AVALIAÇÃO DE TRÊS CEPAS DE VÍRUS RÁBICO, ANTIGENICAMENTE DISTINTAS, EM CAMUNDONGOS. II - ESTUDO DA DISSEMINAÇÃO VIRAL, POR DIFERENTES ÓRGÃOS*
}

\author{
Pedro Manuel Leal Germano** \\ Omar Miguel*** \\ Masaio Mizuno Ishizuka** \\ Egon Vieira da Silva****
}

\begin{abstract}
GERMANO, P.M.L. et al. Avaliação de três cepas de vírus rábico, antigenicamente distintas, em camundongos. II - Estudo da disseminação viral por diferentes órgãos. Rev. Saúde públ., S. Paulo, 22: 473$8,1988$.

RESUMO: Estudou-se, comparativamente, o grau de disseminação de três cepas de vírus rábico, duas de origem de cão, Jales e Nigéria, e uma de origem de morcego, DR 19, com perfis antigênicos do nucleocapside distintos. Estas cepas foram inoculadas por via intramuscular, na face interna da coxa, em dois grupos de camundongos, com 21 e 28 dias de idade. Os animais foram mantidos em observação por um período total de 30 dias, e dos animais vitimados pela infecção, foram coletados diferentes órgăos, músculo lingual, coração, pulmão, rim e figado, além do cérebro e da medula espinal, para avaliar-se 0 grau de disseminação de cada cepa viral, através da prova de imunofluorescência direta (IFD). Os resultados obtidos evidenciaram que os decalques de cérebro e de medula espinal apresentaram total concordância na prova de IFD, constatando-se as maiores diferenças com as cepas Jales e Nigéria, situando-se a cepa DR 19, intermediariamente, a estas duas. O músculo lingual foi o brgão que apresentou maior frequiência de positividade para ambos os grupos etários e para as três cepas virais.
\end{abstract}

UNITERMOS: Vírus da raiva. Raiva.

\section{INTRODUÇÃO}

$\mathrm{O}$ vírus rábico tem sido detectado, sistematicamente, em quase todos os tecidos extraneurais do organismo de hospedeiros humanos, domésticos e silvestres, tanto em condições naturais quanto experimentais (Alvarado e col.', 1976; Fekadu e Shaddock ${ }^{11}$, 1984). Para a identificação das partículas virais, nesses tecidos, tem sido utilizada, principalmente, a técnica de imunofluorescência direta (Schneider ${ }^{17}, 1975$ ).

A capacidade de disseminação do vírus pelos diferentes tecidos parece estar relacionada, principalmente, com o tipo de cepa viral e o grau de suscetibilidade do hospedeiro (Fekadu e Shaddock ${ }^{11}$, 1984; Dietzschold e col ${ }^{10}, 1985$ ).

De todos os tecidos extraneurais, as glândulas salivares são as que apresentam maior grau de infectividade, podendo em muitos casos fornecer um título infectante superior ao do próprio tecido nervoso (Charlton e col. ${ }^{4}, 1983$ ). De modo similar, são atingidos o músculo lingual e as papilas linguais (Correa-Giron e $\mathrm{col}^{7}, 1970$ ). Conseqüentemente, o vírus é eliminado com a saliva, podendo esta eliminação ocorrer já alguns dias antes do aparecimento da manifestação clínica (Sikes ${ }^{19}, 1962$ ). Este fato reveste-se de grande importância em epidemiologia, uma vez que um animal ainda livre de suspeição pode já estar transmitindo o vírus rábico a outros hospedeiros suscetíveis, pela saliva.

A disseminação do vírus no trato respiratório passou a ocupar lugar de destaque na epidemiologia da raiva quando, em 1962, Constantines observou a possibilidade da transmissão da raiva por via aerógena. $O$ vírus pode ser recuperado nos pulmôes, após inalação de partículas virais (Constantines, 1962), após a inoculação de suspensões virais (Reagan e col. ${ }^{16}, 1953$ ) e após infecção por via oral (Correa-Giron e col.?, 1970).

Ao nível do sistema circulatório, somente a

* Parte da tese de livre-docência, apresentada à Faculdade de Medicina Veterinária e Zootecnia da USP, subordinada ao título "Estudo da etiopatogenia da raiva: avaliação de três cepas de vírus rábico, antigenicamente distintos em camundongos". Trabalho apresentado no IV Congresso Internacional de Veterinária de Lingua Portuguesa, Såo Paulo, 1987.

** Departamento de Medicina Veterinária Preventiva e Saúde Animal da Faculdade de Medicina Veterinária e Zootecnia da Universidade de São Paulo - Av. Corifeu de Azevedo Marques, 2720 - 05340 - São Paulo, SP - Brasil.

*** Departamento de Prática de Saúde Pública da Faculdade de Saúde Pública de Universidade de São Paulo - Av. Dr. Arnaldo, 715 - 01255 - São Paulo, SP - Brasil.

**** Unidade de Controle de Vacinas Anti-Rábicas do Laboratório Regional de Apoio Animal (LARA) de Campinas, do Ministério da Agricultura - Rod. Heitor Penteado, Km 3,5 - 13100 - Campinas, SP - Brasil. 
partir do coração, tem sido possível o isolamento do vírus rábico (Fekadu e Shaddock ${ }^{11}, 1984$ ), embora ainda seja discutível a possibilidade de isolamento do vírus a partir do sangue de doentes (Schneider ${ }^{17}, 1975$ ).

$\mathrm{O}$ vírus rábico tem sido isolado a partir do parênquima renal (Reagan e col. ${ }^{16}, 1953$ ), dos tecidos neuroepiteliais dos uretéres, bexiga e uretra, e, também, a partir da urina (Debbie e Trimarchi ${ }^{9}$, 1970; Fischman e Schaeffer ${ }^{12}$, 1971). Este fato deu origem à hipótese de que as partículas virais, eliminadas com a urina, poderiam, eventualmente, ser inaladas por outros animais, constituindo importante via de eliminação do vírus rábico, principalmente na epidemiologia da raiva silvestre, notadamente entre raposas (Schneider ${ }^{17}, 1975$ ).

Ao nível do trato digestivo tem-se constatado a infecção das mucosas gástrica (Correa-Giron e col. ${ }^{7}, 1970$ ) e intestinal (Atanasiu e col. ${ }^{2}$, 1970), bem como a presença de partículas virais no pâncreas (Fekadu e Shaddock"1, 1984) e no fígado (Schneider e Hamann ${ }^{18}$, 1969); todavia, apesar da possibilidade do vírus rábico vir a ser eliminado pelas fezes, acredita-se que o mesmo seja inativado pelas enzimas digestivas (Schneider ${ }^{17}, 1975$; Fekadu e Shaddock ${ }^{11}, 1984$ ) tornando-as vias de eliminação de menor valor na epidemiologia da raiva.

O estudo da disseminação de partículas virais rabicas por diferentes órgãos tem sido merecedor de inúmeros trabalhos ${ }^{5,9,10,13,19}$, notadamente no que concerne ao comportamento de diferentes cepas de vírus da raiva frente a sistemas biológicos diversos.

O presente trabalho objetiva estudar o comportamento de três cepas de vírus rábico, distintas antigenicamente, duas originadas a partir de cão e outra originada de morcego, frente a dois grupos etários diferentes de camundongos normais, considerando o grau de disseminação de partículas víricas por diferentes órgãos.

\section{MATERIAL E MÉTODOS}

\section{Órgãos}

Foram utilizados diferentes órgãos, coletados a partir de camundongos, inoculados experimentalmente, por via intramuscular, com 3 cepas de vírus rábico, antigenicamente distintas, de acordo com o procedimento descrito por Germano e col. ${ }^{13}$ (1988).

Assim, foram coletados, cérebro, medula espinal dorsal, músculo lingual, coração, pulmão, fígado e rim, dos animais dos Grupos I (subdivididos nos sub-grupos 1, 2 e 3 ) e II (subdivididos nos sub-grupos 4,5 e 6 ) vitimados pe- la infecção rábica, de acordo com o seguinte esquema:

- Sub-grupos 1 e 4: animais inoculados com a cepa Jales;

- Sub-grupos 2 e 5: animais inoculados com a cepa DR 19;

- Sub-grupos 3 e 6: animais inoculados com a cepa Nigéria.

\section{Imunofluorescência Direta (IFD)}

A prova de IFD foi realizada de acordo com a técnica descrita por Dean e Abelseth ${ }^{8}$ (1973), utilizando-se dois pares de lâminas para cada órgão examinado.

O conjugado foi utilizado na diluição 1:80 e a suspensão de CVS (Challenge Virus Standard) apresentou um título igual a $10^{7,1}$ DL50/0,03 ml.

Utilizou-se microscópio binocular, marca Zeiss, com objetiva de imersão $40 \mathrm{X}$ provida de diafragma, ocular $10 \mathrm{X}$, campo escuro, com condensador cardióide, lâmpada HBO 200, filtro excitador VG1 e filtro barreira Zeiss 43 .

\section{Análise Estatística}

Aplicou-se a distribuição normal com o teste " $Z$ ", para duas proporçס̃es com aproximação normal (Berquó $\left.{ }^{3}, 1980\right)$ para verificar a possível existência de diferenças entre os resultados de ambos os grupos etários, considerando-se a cepa viral e a presença de partículas fluorescentes específicas nos órgãos estudados. Aplicou-se o mesmo procedimento estatístico para constatar a existência ou não de diferenças entre as cepas, duas a duas, e a presença de partículas virais nos órgãos, levando-se em conta ambos os grupos itários.

Adotou-se como nível de rejeição, alfa igual a 0,05 e o valor crítico de " $Z$ " de alfa igual a 1,96 .

\section{RESULTADOS}

As Tabelas de 1 a 3, apresentam os resultados da prova de imunofluorescência direta praticada sobre decalques dos diversos órgãos selecionados para avaliar o grau de disseminação das diferentes cepas de vírus rábico empregadas, levando-se em consideração os dois grupos etários.

A partir dos resultados referidos nas Tabelas de 1 a 3 , procedeu-se à análise estatística. Assim, nas Tabelas 4 e 5 são apresentados os valores da estatística " $Z$ " e sua correspondente significância.

Na Figura, construída a partir dos dados apresentados nas Tabelas de 1 a 3, são demons- 
TABELA 1

Resultados percentuais da prova de imunofluorescência direta realizada em decalques de órgãos de camundongos, inoculados experimentalmente, por via intramuscular, com vírus rábico de origem de cão, cepa Jales, segundo o grupo etário. São Paulo, 1986.

\begin{tabular}{|c|c|c|c|c|c|c|c|c|c|c|c|c|}
\hline \multirow{3}{*}{$\frac{\mathrm{GE}}{\mathrm{IFD}}$} & \multicolumn{6}{|c|}{$21 \mathrm{Dias}$} & \multicolumn{6}{|c|}{28 Dias } \\
\hline & \multicolumn{2}{|c|}{ Positivo } & \multicolumn{2}{|c|}{ Negativo } & \multicolumn{2}{|c|}{ Total } & \multicolumn{2}{|c|}{ Positivo } & \multicolumn{2}{|c|}{ Negativo } & \multicolumn{2}{|c|}{ Total } \\
\hline & $\mathbf{F}$ & $\%$ & $\mathbf{F}$ & $\%$ & $\mathrm{~F}$ & $\%$ & $\mathrm{~F}$ & $\%$ & $\mathbf{F}$ & $\%$ & F & $\%$ \\
\hline $\begin{array}{l}\text { Cérebro } \\
\text { Medula } \\
\text { Língua } \\
\text { Coração } \\
\text { Pulmão } \\
\text { Rim } \\
\text { Fígado }\end{array}$ & $\begin{array}{r}24 \\
24 \\
11 \\
7 \\
7 \\
4 \\
2\end{array}$ & $\begin{array}{r}100,0 \\
100,0 \\
45,8 \\
29,2 \\
29,2 \\
16,7 \\
8,3\end{array}$ & $\begin{array}{r}0 \\
0 \\
13 \\
17 \\
17 \\
20 \\
22\end{array}$ & $\begin{array}{r}0,0 \\
0,0 \\
54,2 \\
70,8 \\
70,8 \\
83,3 \\
91,7\end{array}$ & $\begin{array}{l}24 \\
24 \\
24 \\
24 \\
24 \\
24 \\
24\end{array}$ & $\begin{array}{l}100,0 \\
100,0 \\
100,0 \\
100,0 \\
100,0 \\
100,0 \\
100,0\end{array}$ & $\begin{array}{r}14 \\
14 \\
11 \\
3 \\
2 \\
1 \\
1\end{array}$ & $\begin{array}{r}100,0 \\
100,0 \\
78,6 \\
21,4 \\
14,3 \\
7,1 \\
7,1\end{array}$ & $\begin{array}{r}0 \\
0 \\
3 \\
11 \\
12 \\
13 \\
13\end{array}$ & $\begin{array}{r}0,0 \\
0,0 \\
21,4 \\
78,6 \\
85,7 \\
92,9 \\
92,9\end{array}$ & $\begin{array}{l}14 \\
14 \\
14 \\
14 \\
14 \\
14 \\
14\end{array}$ & $\begin{array}{l}100,0 \\
100,0 \\
100,0 \\
100,0 \\
100,0 \\
100,0 \\
100,0\end{array}$ \\
\hline
\end{tabular}

$\mathrm{GE}=$ Grupo Etário / IFD - Imunofluorescência direta

$F=$ Frequência $/ \%=$ Percentagem

TABELA 2

Resultados percentuais da prova de imunofluorescência đireta realizada em decalques de órgâos de camundongos, inoculados experimentalmente, por via intramuscular, com vírus rábico de origem de morcego, cepa DR 19, segundo o grupo etário. São Paulo, 1986.

\begin{tabular}{|c|c|c|c|c|c|c|c|c|c|c|c|c|}
\hline \multirow{3}{*}{$\frac{\text { GE }}{\text { IFD }}$} & \multicolumn{6}{|c|}{21 Dias } & \multicolumn{6}{|c|}{28 Dias } \\
\hline & \multicolumn{2}{|c|}{ Positivo } & \multicolumn{2}{|c|}{ Negativo } & \multicolumn{2}{|c|}{ Total } & \multicolumn{2}{|c|}{ Positivo } & \multicolumn{2}{|c|}{ Negativo } & \multicolumn{2}{|c|}{ Total } \\
\hline & $\mathbf{F}$ & $\%$ & F & $\%$ & $\mathrm{~F}$ & $\%$ & $\mathbf{F}$ & $\%$ & $F$ & $\%$ & $\mathrm{~F}$ & $\%$ \\
\hline $\begin{array}{l}\text { Cérebro } \\
\text { Medula } \\
\text { Língua } \\
\text { Coração } \\
\text { Pulmão } \\
\text { Rim } \\
\text { Fígado }\end{array}$ & $\begin{array}{r}27 \\
27 \\
22 \\
13 \\
14 \\
6 \\
7\end{array}$ & $\begin{array}{r}100,0 \\
100,0 \\
81,5 \\
48,1 \\
51,8 \\
22,2 \\
25,9\end{array}$ & $\begin{array}{r}0 \\
0 \\
5 \\
14 \\
13 \\
21 \\
20\end{array}$ & $\begin{array}{r}0,0 \\
0,0 \\
18,5 \\
51,9 \\
48,2 \\
77,8 \\
74,1\end{array}$ & $\begin{array}{l}27 \\
27 \\
27 \\
27 \\
27 \\
27 \\
27\end{array}$ & $\begin{array}{l}100,0 \\
100,0 \\
100,0 \\
100,0 \\
100,0 \\
100,0 \\
100,0\end{array}$ & $\begin{array}{r}27 \\
27 \\
22 \\
13 \\
10 \\
10 \\
5\end{array}$ & $\begin{array}{r}100,0 \\
100,0 \\
81,5 \\
48,1 \\
37,0 \\
37,0 \\
18,5\end{array}$ & $\begin{array}{r}0 \\
0 \\
5 \\
14 \\
17 \\
17 \\
22\end{array}$ & $\begin{array}{r}0,0 \\
0,0 \\
18,5 \\
51,9 \\
63,0 \\
63,0 \\
81,5\end{array}$ & $\begin{array}{l}27 \\
27 \\
27 \\
27 \\
27 \\
27 \\
27\end{array}$ & $\begin{array}{l}100,0 \\
100,0 \\
100,0 \\
100,0 \\
100,0 \\
100,0 \\
100,0\end{array}$ \\
\hline
\end{tabular}

$\mathrm{GE}=$ Grupo Etário $/ \mathrm{IFD}=$ Imunofluorescência đireta

$F=$ Frequência $/ \%=$ Percentagem

TABELA 3

Resultados percentuais da prova de imunofluorescência direta realizada em decalques de órgãos de camundongos, inoculados experimentalmente, por via intramuscular, com vírus rábico de origem de cão, cepa Nigéria, segundo o grupo etário. São Paulo, 1986.

\begin{tabular}{|c|c|c|c|c|c|c|c|c|c|c|c|c|}
\hline \multirow{3}{*}{$\frac{\text { GE }}{\text { IFD }}$} & \multicolumn{6}{|c|}{$21 \mathrm{Dias}$} & \multicolumn{6}{|c|}{28 Dias } \\
\hline & \multicolumn{2}{|c|}{ Positivo } & \multicolumn{2}{|c|}{ Negativo } & \multicolumn{2}{|c|}{ Total } & \multicolumn{2}{|c|}{ Positivo } & \multicolumn{2}{|c|}{ Negativo } & \multicolumn{2}{|c|}{ Total } \\
\hline & $\mathbf{F}$ & $\%$ & F & $\%$ & F & $\%$ & $\mathbf{F}$ & $\%$ & $\mathbf{F}$ & $\%$ & $\mathbf{F}$ & $\%$ \\
\hline $\begin{array}{l}\text { Cérebro } \\
\text { Medula } \\
\text { Língua } \\
\text { Coração } \\
\text { Pulmão } \\
\text { Rim } \\
\text { Fígado }\end{array}$ & $\begin{array}{l}32 \\
32 \\
31 \\
32 \\
25 \\
29 \\
14\end{array}$ & $\begin{array}{r}100,0 \\
100,0 \\
96,9 \\
100,0 \\
78,1 \\
90,6 \\
43,8\end{array}$ & $\begin{array}{r}0 \\
0 \\
1 \\
0 \\
7 \\
3 \\
18\end{array}$ & $\begin{array}{r}0,0 \\
0,0 \\
3,1 \\
0,0 \\
21,9 \\
9,4 \\
56,2\end{array}$ & $\begin{array}{l}32 \\
32 \\
32 \\
32 \\
32 \\
32 \\
32\end{array}$ & $\begin{array}{l}100,0 \\
100,0 \\
100,0 \\
100,0 \\
100,0 \\
100,0 \\
100,0\end{array}$ & $\begin{array}{r}14 \\
14 \\
14 \\
13 \\
8 \\
11 \\
4\end{array}$ & $\begin{array}{r}100,0 \\
100,0 \\
100,0 \\
92,8 \\
57,1 \\
78,6 \\
28,6\end{array}$ & $\begin{array}{r}0 \\
0 \\
0 \\
1 \\
6 \\
3 \\
10\end{array}$ & $\begin{array}{r}0,0 \\
0,0 \\
0,0 \\
7,2 \\
42,9 \\
21,4 \\
71,4\end{array}$ & $\begin{array}{l}14 \\
14 \\
14 \\
14 \\
14 \\
14 \\
14\end{array}$ & $\begin{array}{l}100,0 \\
100,0 \\
100,0 \\
100,0 \\
100,0 \\
100,0 \\
100,0\end{array}$ \\
\hline
\end{tabular}

GE $=$ Grupo Etário $/$ IFD = Imunofluorescência direta

$\mathrm{F}=$ Frequência $/ \%=$ Percentagem 

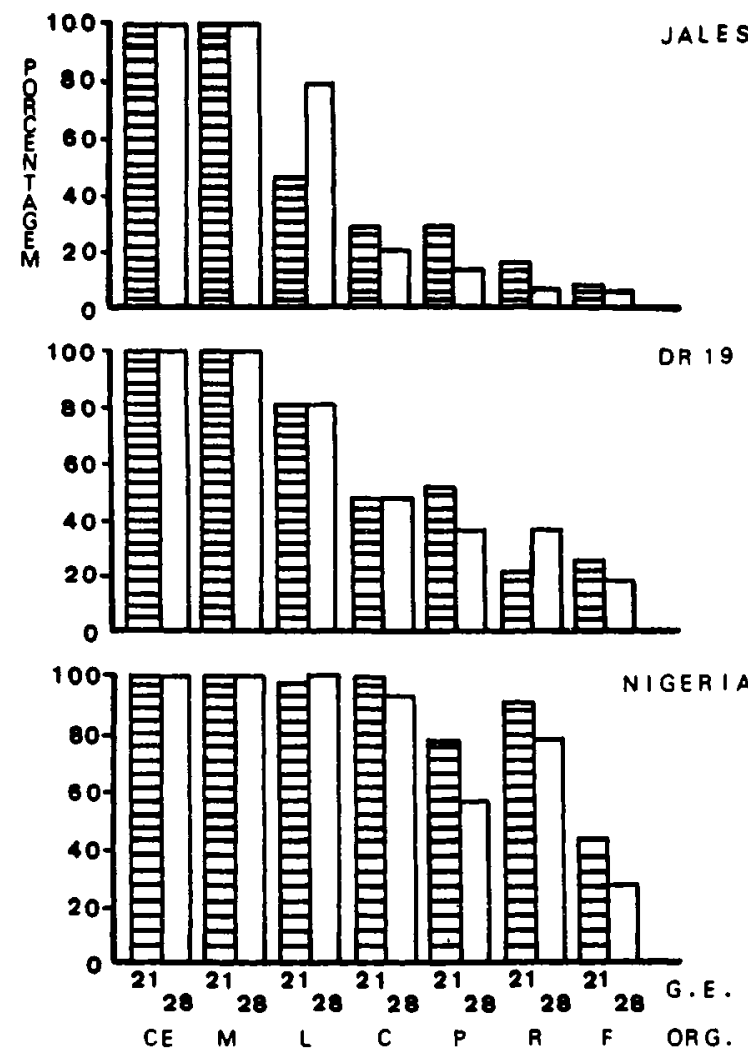

Fig. - Resultados percentuais da prova de imunofluorescência direta, realizada em decalques de órgāos de camundongos inoculados experimentalmente, por via intramuscular, com vírus rábico, segundo o grupo etário e a cepa do vírus. São Paulo, 1986.

$\begin{array}{lll}\text { GE } & =\text { Grupo E tário } & \mathrm{C}=\text { Coração } \\ \mathrm{ORG}=\text { Orgão } & \mathbf{P}=\text { Pulmão } \\ \mathrm{CE}=\text { Cérebro } & \mathrm{R}=\mathbf{R i m} \\ \mathrm{M} & =\text { Medula Espinal } & \mathrm{F}=\text { Fígado } \\ \mathrm{L} & =\text { Músculo Lingual } & \end{array}$

trados os resultados da prova de imunofluorescência direta sobre decalques de órgãos, revelando a proporção de positividade de cada um deles para as diferentes cepas de vírus rábico, considerada de per si.

\section{DISCUSSÃO}

$O$ exame das Tabelas de 1 a 3 permitiu verificar que todos os animais que morreram ao longo do periodo de observação clínica tiveram os decalques de cérebro e medula espinal, simultaneamente, positivos pela prova de imunofluorescência direta. Estes resultados não só confirmaram a raiva como causa mortis, como também comprovaram a total concordância existente entre estas duas regioes do SNC (Sistema Nervoso Central), para efeito de diagnóstico la- boratorial, tal como havia sido constatado por Lee e Becker ${ }^{14}$ (1972).

Em relação aos outros órgãos selecionados, constatou-se não haver diferenças estatisticamente significantes (Tabelas 4 e 5) entre os grupos etários, para cada uma das cepas virais consideradas, exceção feita ao músculo lingual dos animais inoculados com a cepa Jales, onde se observou maior proporção de positividade nos camundongos com 28 dias de idade.

A comparação das frequêencias de positividade, entre as cepas virais, tomadas duas a duas, possibilitou constatar a ausência quase total de diferenças, estatisticamente significantes, entre as cepas Jales e DR 19, exceto no que se refere ao músculo lingual dos animais do grupo com 21 dias de idade, onde a proporção de positividade dos camundongos inoculados com a cepa Jales foi menor que a da cepa DR 19. O inverso ocorreu entre as cepas Jales e Nigéria, onde se constatou diferenças estatisticamente significantes entre quase todas as frequeencias de positividade, à exceção do músculo lingual e do fígado dos animais pertencentes ao grupo com 28 dias de idade, quando estas proporções não apresentaram diferenças estatisticamente significantes.

No que concerne à comparação das freqüências de positividade, entre as cepas DR 19 e Nigéria, não se observaram diferenças estatisticamente significantes entre as proporçōes de positividade do músculo lingual e do fígado, ocorrendo o inverso com o coração e rim, para ambos os grupos etários. Com relação ao pulmão, a diferença foi estatisticamente significante somente no grupo de animais com 21 dias de idade, onde esta proporção foi mais elevada nos camundongos inoculados com a cepa Nigéria. Todas estas diferenças podem ser observadas na Figura

\section{TABELA 4}

Valores da estatística " $Z$ " e sua significância, quando da utilização do teste de duas proporçốes, para a comparação dos resultados obtidos entre os grupos etários e a presença de partículas específicas fluorescentes nos diversos órgäos de camundongos, inoculados experimentalmente, por via intramuscular, com vírus rábico, segundo a cepa viral. São Paulo, 1986.

\begin{tabular}{llll}
\hline \multirow{2}{*}{ Orgãos } & \multicolumn{3}{c}{ Vírus } \\
\cline { 2 - 4 } & Jales & DR 19 & Nigéria \\
\hline Língua & $1,98 *$ & $0,00 \mathrm{NS}$ & $0,67 \mathrm{NS}$ \\
Coração & $0,53 \mathrm{NS}$ & $0,00 \mathrm{NS}$ & $1,53 \mathrm{NS}$ \\
Pulmão & $1,04 \mathrm{NS}$ & $1,09 \mathrm{NS}$ & $1,46 \mathrm{NS}$ \\
Rim & $0,84 \mathrm{NS}$ & $1,19 \mathrm{NS}$ & $1,11 \mathrm{NS}$ \\
Fígado & $0,13 \mathrm{NS}$ & $0,65 \mathrm{NS}$ & $0,97 \mathrm{NS}$ \\
\hline
\end{tabular}

* = Significante $/ \mathrm{NS}=$ Nẫo Significante 


\section{TABELA 5}

Valores da estatística " $Z$ " e sua significância, quando da utilização do teste de duas proporções, para a comparação dos resultados obtidos entre as cepas de vírus rábico, duas a duas, o grupo etário e a presença de partículas específicas fluorescentes nos diversos órgãos de camundongos, inoculados experimentalmente, por via intramuscular, com vírus rábico. São Paulo, 1986.

\begin{tabular}{|c|c|c|c|c|c|c|c|}
\hline Virus & \multicolumn{3}{|c|}{ Jales X DR 19} & \multicolumn{2}{|c|}{ Jales X Nigéria } & \multicolumn{2}{|c|}{ DR 19 X Nigéria } \\
\hline Orgãos & GE & 21 Dias & 28 Dias & 21 Dias & 28 Dias & 21 Dias & 28 Dias \\
\hline $\begin{array}{l}\text { Língua } \\
\text { Coração } \\
\text { Pulmão } \\
\text { Rim } \\
\text { Fígado }\end{array}$ & & $\begin{array}{l}2,66 * \\
1,38 \mathrm{NS} \\
1,64 \mathrm{NS} \\
0,50 \mathrm{NS} \\
1,65 \mathrm{NS}\end{array}$ & $\begin{array}{l}0,22 \mathrm{NS} \\
1,66 \mathrm{NS} \\
1,52 \mathrm{NS} \\
2,05 \mathrm{NS} \\
0,98 \mathrm{NS}\end{array}$ & $\begin{array}{l}4,37 * \\
5,70 * \\
3,66 * \\
5,56 * \\
2,91 *\end{array}$ & $\begin{array}{l}1,83 \mathrm{NS} \\
3,82 * \\
2,36 * \\
3,82 * \\
1,48 \mathrm{NS}\end{array}$ & $\begin{array}{l}1,95 \mathrm{NS} \\
4,67 * \\
2,40 * \\
5,33 * \\
1,43 \mathrm{NS}\end{array}$ & $\begin{array}{l}1,72 \text { NS } \\
2,82 * \\
1,23 \mathrm{NS} \\
2,53 * \\
0,74 \mathrm{NS}\end{array}$ \\
\hline
\end{tabular}

* = Significante / NS = Não Significante

O músculo lingual, para todas as cepas, foi o que apresentou maior grau de positividade. $O$ encontro de partículas virais nesse órgão não é raro, e parece não ser dependente do tipo de via de inoculação e do sistema biológico considerados (Fischmann e Schaeffer ${ }^{12}$, 1971; Fekadu e Shaddock"1, 1984).

As frequêencias de positividade, encontradas ao nivel do coração e do pulmão, foram muito próximas, sendo semelhantes aos resultados encontrados por Schneider e Hamann ${ }^{18}$ (1969), quando de inoculações intrapodais em camundongos.

Em relação ao rim, o grau de disseminação do vírus rábico parece estar diretamente relacionado ao tipo de cepa viral, quando a frequêencia máxima de positividade, frente à cepa Nigéria, no grupo de camundongos com 21 dias atingiu $90,6 \%$ contra $16,7 \%$ do mesmo grupo etário, face à cepa Jales.

De todos os orgãos pesquisados, o fígado foi - que apresentou menor grau de disseminação, embora a freqüência de positivos tivesse variado com cada uma das cepas virais.

Do ponto de vista epidemiológico, assume comprovada importância a infecção do músculo lingual, a qual guarda relação com a infecção das glândulas salivares (Correa-Giron e col. ${ }^{7}$, 1970), e a presença de partículas virais ao nível do pulmão, as quais podem, eventualmente, ser exaladas com a respiração ou através de secreçס̄es nasais (Constantine e col. ${ }^{6}, 1972$; Murphy $\left.{ }^{15}, 1983\right)$. O rim dos animais infectados pode contribuir para a eliminação de partículas virais infectantes através da urina (Schneider ${ }^{17}$, 1975), embora este fato nem sempre seja observado (Fekadu e Shaddock ${ }^{11}, 1984$ ).

A partir destes resultados pode-se depreender que o grau de disseminação de partículas virais pelos diversos órgãos examinados, depende, fundamentalmente, da cepa de vírus rábico considerada. Esta observação confirma a hipótese, recentemente formulada por Fekadu e Shaddock ${ }^{11}$ (1984), quando da inoculação em cães, de duas cepas rábicas, aparentemente distintas.

No estudo da disseminação de partículas virais, em órgãos não nervosos, foi possível constatar diferenças marcantes entre as cepas Jales e Nigéria. Enquanto que os orgãos provenientes dos camundongos vitimados pela cepa Nigéria atingiram as maiores proporçðes de positividade, através da prova de imunofluorescência direta, o contrário verificou-se com a cepa Jales, onde esta proporção ficou bem aquém da primeira. Em relação à cepa DR 19, estas proporções de positividade registraram valores próximos, caracterizando-a, novamente, como distinta das demais, em relação, também, ao grau de disseminação de partículas virais pelos diversos órgãos examinados.

\section{CONCLUSÕES}

$O$ cérebro e a medula espinal revelaram-se sempre positivos à pesquisa de corpúsculos de Negri fluorescentes, independentemente, da cepa de vírus rábico e do grupo etário.

A disseminação de partículas virais pelos diferentes órgãos não nervosos, dependeu, fundamentalmente, de cada cepa de vírus rábico, não sofrendo, todavia, interferência da idade dos animais.

A cepa Nigéria foi a que apresentou o maior grau de disseminação de partículas virais, por órgãos não nervosos, seguida, respectivamente, pelas cepas DR 19 e Jales.

Dos órgãos pesquisados, o músculo lingual foi o que apresentou frequiências de positividade mais elevadas, independentemente da cepa de vírus rábico e da idade dos animais. 
GERMANO, P.M.L. et al. [Evaluation of three antigenically different rabies virus strains in mice. II Study of the viral dissemination in different organs]. Rev. Saúde públ., S. Paulo, 22:473-8, 1988.

\begin{abstract}
A study was conducted to compare three strains of rabies virus, two of them, Jales and Nigeria, isolated from dogs, and the other DR 19, from vampire bats, with different nucleo-capside antigenic characteristics. These strains were intramuscularly inoculated in the inner side of the thigh of 21 and 28 day-old mice. The animals were observed for 30 days and different organs: brain, spinal cord, tongue, heart, lung, kidney and liver were collected from the animals which died of rabies for the dissemination study by the immunofluorescent antibody technique (IFA). This technique showed complete agreement between brain and spinal cord. The greatest differences in dissemination were observed between Jales and Nigeria strains. The results observed for the DR 19 strain were situated between those of the two dog strains. The greates degree of dissemination was observed in the tongue for both age group and for all the strains.
\end{abstract}

UNITERMS: Rabies virus. Rabie.

\title{
REFERÊNCIAS BIBLIOGRÁFICAS
}

1. ALVARADO R,. J.F.; DIAMANTE B., A.; DELGADO C., H.; CUBILLAN, E. Diagnostico de virus rabico en tejidos no nerviosos. Vet. trop., 1:73-8, 1976.

2. ATANASIU, P.; GAMET, A.; TSIANG, H.; DRAGONAS, P.; LEPINE, P. Nouvelles donnés sur les voies d'élimination du virus rabique chez les animaux infectés. C. R. Acad. Sci., Paris, 271:2434-6, 1970.

3. BERQUÓ, E. Bioestatística. São Paulo, EPU, 1980.

4. CHARLTON, K.M.; CASEY, G.A.; CAMPBELL, J.B. Experimental rabies in skunks: mechanisms of infection of the salivary glands. Canad. J. comp. Med., 47:363-9, 1983.

5. CONSTANTINE, D.G. Rabies transmission by non bite route. Publ. Hlth Rep., 77:287-9, 1962.

6. CONSTANTINE, D.G.; EMMONS, R.W.; SOODIE, J.D. Rabies virus in nasal mucosa of naturaly infected bats. Science, 175:1255-6, 1972.

7. CORREA-GIRON, E.P.; ALLEN, R.; SULKIN, S.E. The infectivity and pathogenesis of rabies virus ad. ministered orally. Amer. J. Epidem., 91:203-15, 1970.

8. DEAN, D.J. \& ABELSETH, M.K. The fluorescent antibody test. In: World Health Organization. Laboratory techniques in rabies. $3^{\text {rd }}$. ed. Geneva, 1973. p. 73-84.

9. DEBBIE, J.G. \& TRIMARCHI, C.V. Panotropism of rabies virus in free-ranging rabid red fox Vulpes fulva. J. Wildl. Dis., 6:500-6, 1970.

10. DIETZSCHOLD, B.; WIKTOR, T.J.; TROJANOWSKI, J.Q.; MACFARLANE, R.I.; WUNNER, W.H.; TORRES-ANJEL, M.J.; KOPROWSKI, H. Differences in cell-to-cell spread of pathogenic and apathogenic rabies virus in vivo and in vitro. $J . \mathrm{Vi}$ rol., 56:12-8, 1985.
11. FEKADU, M. \& SHADDOCK, J.H. Peripheral distribution of virus in dogs inoculated with two strains of rabies virus. Amer. J. vet. Res., 45:724-9, 1984.

12. FISCHMANN, H.R. \& SCHAEFFER, M. Pathogenesis of experimental rabies as revealed by immunofluorescence. Ann. N.Y. Acad. Sci., 177:78-97, 1971.

13. GERMANO, P.M.L.; SILVA, E.V.; SUREAU, P. Determinação do perfil antigênico de 3 cepas de virus rábico, isoladas no Brasil, através da técnica dos anticorpos monoclonais antinucleocapside. Rev. Fac. Med. vet. Zootec. Univ. S. Paulo, 25, 1988 [no prelo].

14. LEE, T.K. \& BECKER, M. Validity of spinal cord examination as a substitute procedure for routine rabies diagnosis. Appl. Microbiol, 24:714-6, 1972.

15. MURPHY, F.A. Pathogenesis of rabies. In: Fromm Laboratories. Report on rabies. Princeton Junction, Veterinary Learning Systems, 1983. p. 7-10.

16. REAGAN, R.L.; DAY, W.C.; MOORE, S.; KEHNE, E.F.; BRUECKNER, A.L. Response of the Syrian hamster to two strains of rabies street virus by rectal instillation. Amer. J. trop. Med., 2:70-3, 1953.

17. SCHNEIDER, L.G. Spread of virus from the central nervous system. In: Baer, G.M., ed. The natural history of rabies. New York, Academic Press, 1975. v.1, p. 273-301.

18. SCHNEIDER, L.G. \& HAMANN, I. Die Pathogenese der Tollwut bei der Maus. Zblt. Bakt. I. Abt. Orıg., 212:13-41, 1969.

19. SIKES, R.W. Pathogenesis of rabies in wild life. I. Comparative effect of varying doses of rabies virus inoculated into foxes and skunks. Amer. J. vet. Res., 23:1041-7, 1962.

Recebido para publicação em 28/10/1987 Reapresentado em $2 / 5 / 1988$

Aprovado para publicação em 10/6/88 